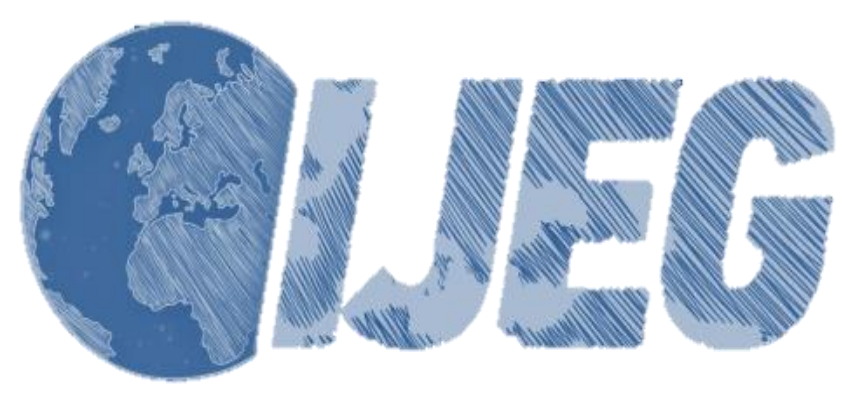

International Journal of Engineering and Geosciences (IJEG),

Vol; 4, Issue;3, pp. 106-114, October, 2019, ISSN 2548-0960, Turkey, DOI: 10.26833 /ijeg.492496

\title{
PERFORMANCE OF NETWORK RTK CORRECTION TECHNIQUES (FKP, MAC and VRS) UNDER LIMITED SKY VIEW CONDITION
}

\author{
Hüseyin Pehlivan ${ }^{1}$, Mert Bezcioğlu ${ }^{1}$ and Y1lmaz Muhammet $^{2}$ \\ ${ }^{1}$ Gebze Technical University, Engineering Faculty, Department of Geomatics Engineering, Gebze-Kocaeli, Turkey \\ ( hpehlivan@ gtu.edu.tr, mbezcioglu@gtu.edu.tr ); ORCID 0000-0002-0018-6912 ; ORCID 0000-0001-7179-8361 \\ ${ }^{2}$ Division of Geodetic and Geographical Information Technologies, Graduate School of Natural and Applied Sciences, \\ Gebze Technical University, Gebze-Kocaeli, Turkey \\ (muhammet@geomatikhizmetler.com.tr ); ORCID 0000-0002-2265-035X
}

*Corresponding Author, Received: 12/05/2018, Accepted: 27/03/2019

\begin{abstract}
In recent years, the continuously operating reference station - Turkey (CORS-TR) system has been widely used in engineering and cadastral work in Turkey due to ease of use, low cost, and national legislative requirements. In this study, long-term Network RTK (Real-time Kinematic) data were collected under $10^{\circ}, 20^{\circ}, 30^{\circ}$ and $40^{\circ}$ satellite views using a different approach from previous work. In order to evaluate the positioning performance of the system, the measurements were undertaken at different elevation angles (open, partially blocked and extremely blocked) and by considering three different correction techniques (FKP, VRS and MAC), and the results were evaluated in terms of repeatability. From the analysis of the data, it was understood that the performances of the three correction techniques were generally similar, and even in the case of a limited satellite view, the errors remained below $7 \mathrm{~cm}$ in all three techniques. However, when the 2D and 3D components were analyzed together, VRS technique showed better results than the other two techniques.
\end{abstract}

Keywords: CORS-TR, FKP, MAC, VRS, Network RTK. 


\section{INTRODUCTION}

The global positioning system (GPS) provides precision at $\mathrm{cm}$ level when the position is determined by a relative method (Seeber, 2003). However, requiring at least two receivers, precise trajectory information, and software knowledge, the relative method is not efficient in performing positioning in terms of the time and effort (Gumus et al., 2012; Tusat and Ozyuksel, 2018). Today, developments in GPS/GNSS technology have enabled real-time determination of point locations. First, the classical RTK (Real Time Kinematic) method, which determines point positions in real time at $\mathrm{cm}$ level, was developed. However, in this method, the distance between the reference station and the user is limited to about $10 \mathrm{~km}$ to prevent atmospheric, orbit error, and system-related effects. Therefore, to overcome the limitations in the classical RTK method, a new idea was proposed to set up multiple fixed stations (Raquet, 1998). Since the 1990s, continuously operating reference stations (CORS) are used for the geodetic measurements requiring high accuracy and provide real-time location information at $\mathrm{cm}$ level based on GPS systems (Rizos, 2002; Sunantyo, 2009; Aykut et al., 2015; Bülbül et al., 2017; Bascifci et al., 2018). As a result of the implementation of this idea and the experiences acquired, fixed GNSS networks (RTK network) emerged. GNSS technology (Network-RTK) is now widely used to obtain instantaneous location data with high accuracy. In Turkey, as of May 2009, there are 146 stations the CORSTR (TUSAGA Active) network, four located in the Turkish Republic of Northern Cyprus. This system eliminated dependence on a single reference station and allowed the use of atmospheric modeling of a particular region by utilizing data from a large number of reference stations.

CORS systems provided by the U.S. National Geodetic Survey (NGS) offer three-dimensional position information by evaluating GNSS data, such as carrier phase and pseudo-range observations (https://www.ngs.noaa.gov/CORS/). The CORS Networks consists of fully operational and continuously running stations, which are available to users who wish to correct parameters, such as ionosphere, troposphere and time (Öcalan \& Tunalığlu, 2010). The following three methods are used to calculate the correction parameters in CORS systems: virtual reference station (VRS) (Wanninger, 2003), linear area corrections (FlächenKorrektur-Parameter; FKP) (Wübbena \& Bagge, 1998), and master auxiliary concept (MAC) (Brown et al., 2005). A few studies have investigated which correction method works better for the CORS-TR system. (Gumus et al., 2012), Forty-nine different coordinates obtained from RTK, CORS-TR and IskiCors were corrected using FKP and MAC and the results were compared with the classical local method of total station measurements. The authors reported that the performance of the correction methods for the CORS-TR system was superior. (Bütün and Baybura, 2010), in another study, point coordinates from the CORS-TR stations and static measurement results were compared, and it was determined that the coordinate differences decreased as the measurement period increased. (Gumus et al., 2016), the contribution of the VRS, FKP and MAC to the height data was investigated and VRS was found to provide the most consistent results. (Prrt1, 2016), in a forest area, the performance of VRS and FKP techniques in the CORSTR system was compared with total station measurement and the sensitivity was calculated as $1-3 \mathrm{~cm}$ horizontal and 2-4 cm vertical. (Ögütcü et al., 2016), in an urban area, a few observations were undertaken under the same conditions to analyze the performance of the three different correction techniques, and it was concluded that there was no significant difference between them. (Yildırım et al., 2013), in another study, the authors suggested that the CORS-TR system was suitable for obtaining tectonic movements. (Eren et al., 2009), the performance of the CORS system in three different networks with three different GNSS receivers was analyzed both in real time and in postprocess using FKP, VRS, PRS, and MAC correction techniques, and it was concluded that even in the case of increased base length, these correction techniques yielded successful results.

There are different studies on the precise of CORSTR in the literature. However, to date, no researcher in the national or international arena has clearly explained the contribution of this system to determination of location in case of limited satellite vision through an assessment of long-term CORS measurements using these correction techniques and repeatability of the coordinates. This study adopted a different approach from the literature in that long term CORS-TR data was collected and evaluated based on positional performance, open, partially closed, closed, restricted of satellite visibility, and three different correction techniques.

\subsection{CORS-TR}

The CORS-TR Project, officially started on May 1 , 2006 with the support of TUBITAK, was carried out jointly by Istanbul Kültür University (IKU), General Directorate of Mapping (HGM), General Directorate of Land Registry and Cadastre (TKGM) and completed in December 2008 (Eren et al., 2009). The main purpose of this project was to establish CORS-TR stations that work continuously based on the principles of RTK, contribute weather forecasts, create an atmospheric model via Turkey (Musa et al., 2005), follow tectonic movements, determine crustal deformations, provide positions with the accuracy of $\mathrm{mm}$ level, contribute to earthquake prediction and early warning systems (Brownjohn et al., 2004), and determine the conversion parameters between ED50 and ITRFxx datum (Kempe et al., 2006).

The CORS-TR system consists of 146 stations located in Turkey and the Turkish Republic of Northern Cyprus (Yildırım et al., 2013). The system has three control centers, two of which are in Ankara and one in Istanbul. The coordinates of the control centers are in the ITRF96 datum. The distribution of the CORS-TR stations is shown in Figure 1. When the stations were planned, the most optimal data were taken into consideration to observe the movements of the plate (Mekik et al., 2011; Uzel et al., 2011). These control centers send correction data to the user using FKP, MAC and VRS techniques 
(Gumus et al., 2012).

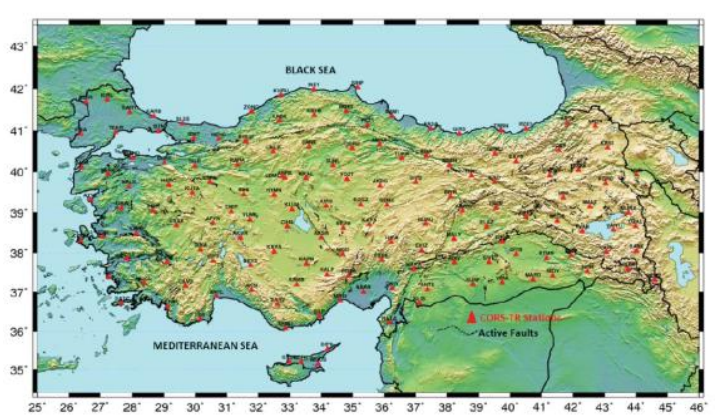

Figure.1 CORS-TR Stations (Y1ldırım et al., 2013)

\subsection{Network RTK correction Techniques}

\subsubsection{FKP}

The FKP technique, also known as the field correction parameter, is one of the first Network-RTK corrections developed by the German SAPOS group (Satellitenpositionierungsdienst der deutschen Landesvermessung) (Kahveci, 2009). The content of FKP corrections is linear ionospheric and geometric correction parameters around the reference station. These linear corrections refer to the changes in east-west and northsouth directions and are used for the exact calculation of the receiver's actual position by interpolation (Prrt1, 2016). The FKP method creates a different FKP plane for each reference surface (Figure 2) (Kahveci, 2009).

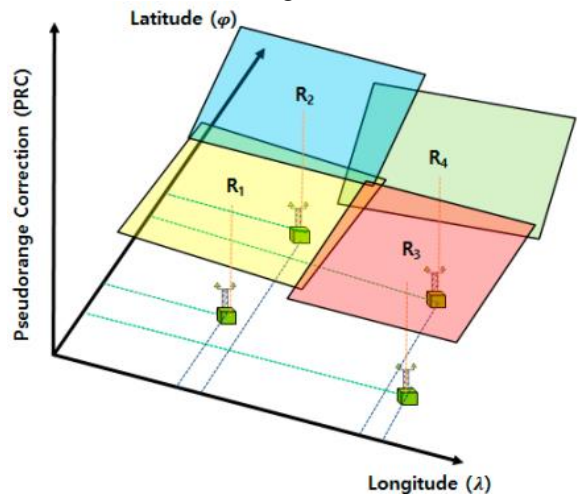

Figure 2: FKP Method for Four Reference Stations (Kim et al., 2017)

\subsubsection{VRS}

VRS is the most widely used augmentation technique worldwide. It provides accurate and precise services for static users. VRS can be used for all GNSS receivers using the RTCM message. VRS also has better performance than other correction techniques. However, corrections are only transmitted after the exact location of the mobile GNSS receiver has been determined (Park, B. et al., 2010). Therefore, if the mobile GNSS receiver has traveled a significant distance within the same campaign period, corrections will not be available for the new recipient location (Landau et al., 2003).

\subsubsection{MAC}

The MAC technique improves the VRS technique and eliminates the disadvantages of FKP, and thus obtains more accurate position information than the other two methods. MAC consists of one master and several subsidiary reference points. Each subsidiary reference point sends measurements to the main control center and an inter-station correction difference is used to estimate the required correction. This correction can also be divided into ionospheric and geometric corrections (Park, B. et al., 2010).

\section{TEST MEASUREMENTS AND METHODOLOGY}

The test was carried out at a selected point from Istanbul (Turkey) and the study area is shown in Figure 3. To assess the performance of correction methods of CORS-TR (Network-RTK), a GEOMAX ZENITH25 GNSS receiver was used. And the coordinates of fixed point were determined as a result of precise static measurements (Figure 4). Test measurements were performed at the same point $\left(28^{\circ} .86382 \mathrm{E}-41^{\circ} .06595 \mathrm{~N}\right)$ on different days. The data of different measurement techniques were collected on different days (between 25.03.2017 and 04.04.2017 dates). In test, different elevation angles and three different correction techniques, namely FKP, MAC and VRS, were used in an open area with no obstacles. For each combination, the observations were performed for 12 to 51 hours with an epoch interval of 1 second. In the test, the data were obtained as north and east coordinates and height, and the analysis of the collected data was conducted with the help of MATLAB software.

Table 1: Duration of Test and Epochs Used

\begin{tabular}{|c|c|c|c|c|}
\hline $\begin{array}{c}\text { Cut-Off } \\
\text { Angle }\end{array}$ & $\begin{array}{c}\text { Correction } \\
\text { Technique }\end{array}$ & Duration & $\begin{array}{c}\text { Epoch } \\
\text { Number }\end{array}$ & $\begin{array}{c}\text { Used } \\
\text { Epoch } \\
\text { Number }\end{array}$ \\
\hline \multirow{3}{*}{$10^{\circ}$} & FKP & $36 \mathrm{~h} 4 \mathrm{~m} 4 \mathrm{~s}$ & 130494 & 109865 \\
\cline { 2 - 5 } & MAC & $44 \mathrm{~h} 15 \mathrm{~m} 46 \mathrm{~s}$ & 159346 & 103364 \\
\cline { 2 - 5 } & VRS & $51 \mathrm{~h} 29 \mathrm{~m} 24 \mathrm{~s}$ & 185364 & 123883 \\
\hline \multirow{3}{*}{$20^{\circ}$} & FKP & $11 \mathrm{~h} 52 \mathrm{~m} 41 \mathrm{~s}$ & 42761 & 42395 \\
\cline { 2 - 5 } & MAC & $11 \mathrm{~h} 54 \mathrm{~m} 45 \mathrm{~s}$ & 42885 & 42321 \\
\cline { 2 - 5 } $30^{\circ}$ & VRS & $20 \mathrm{~h} 17 \mathrm{~m} 48 \mathrm{~s}$ & 73068 & 68583 \\
\hline \multirow{3}{*}{$40^{\circ}$} & FKP & $23 \mathrm{~h} 43 \mathrm{~m} 58 \mathrm{~s}$ & 85438 & 75535 \\
\cline { 2 - 5 } & MAC & $16 \mathrm{~h} 09 \mathrm{~m} 38 \mathrm{~s}$ & 58178 & 44418 \\
\hline & VRS & $19 \mathrm{~h} 36 \mathrm{~m} 31 \mathrm{~s}$ & 70591 & 36644 \\
\hline & FKP & $20 \mathrm{~h} 59 \mathrm{~m} 17 \mathrm{~s}$ & 75557 & 51940 \\
\hline & VRS & - & - & - \\
\hline
\end{tabular}




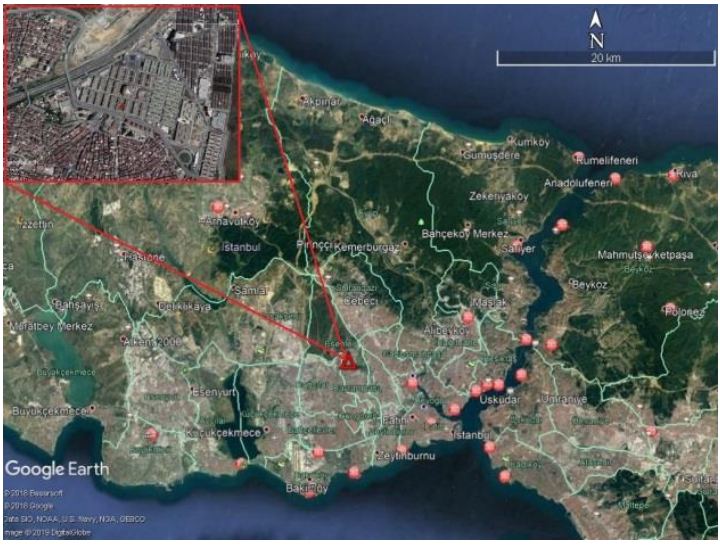

Figure 3. Study area.

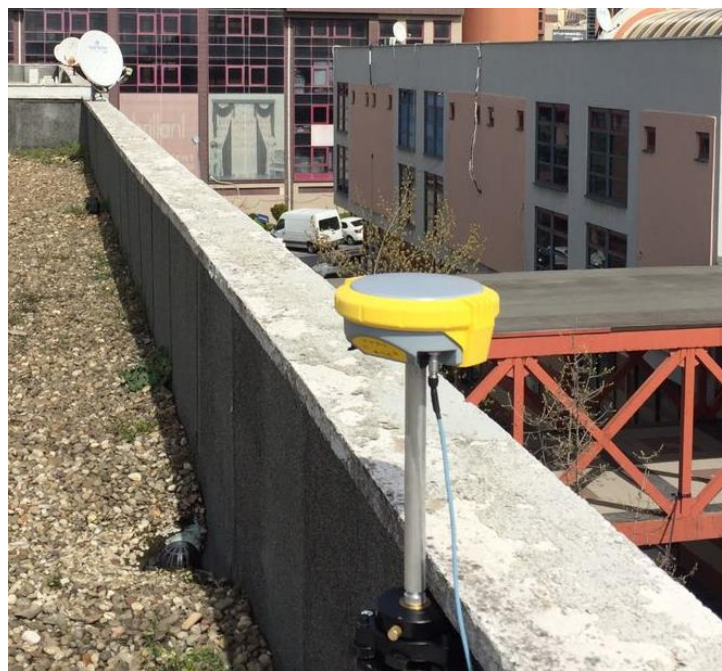

Figure 4. A view from test measurement.

\section{RESULTS AND DISCUSSION}

Histograms of the differences show that the observations collected in the 11 different combinations given in Table 1 and the distribution of differences from the mean value of these observations. The histograms of the differences are given from Figure 5 to Figure 8 . While the time series were obtained based on time, the analysis was performed as epoch-epoch. In the figures, blue, red and green represent the $\mathrm{X}, \mathrm{Y}$ and $\mathrm{h}$ components, respectively. Although the time series collected at an elevation angle of $10^{\circ}$ and $20^{\circ}$ were partially discontinued, they appeared to be more consistent than the data collected at an elevation angle of $30^{\circ}$ and $40^{\circ}$. When the histograms of the data collected in the open, partially closed and extremely closed environments of the satellite view were analyzed, it was seen that the errors in the $\mathrm{X}$ and $\mathrm{Y}$ direction were generally $\pm 2 \mathrm{~cm}$, and those in the $\mathrm{H}$ direction were $\pm 5 \mathrm{~cm}$. The MAC correction technique provided no data under the $40^{\circ}$ satellite view. When the degree of the satellite view decreased, the differences in the time series became clearer. Furthermore, when the histograms data were analyzed under the $40^{\circ}$ satellite view, the Gaussian error distribution was removed and the errors in the $\mathrm{X}, \mathrm{Y}$ direction were $\pm 4 \mathrm{~cm}$ while those in the $\mathrm{h}$ component were $\pm 10 \mathrm{~cm}$.

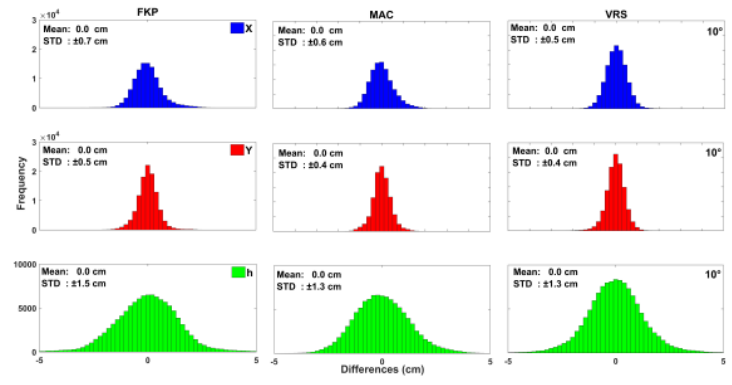

Figure 5. Histograms of differences in measurements of 28-10 hour, using the FKP-MAC-VRS correction techniques (elevation cut-off angle: 10 degree).

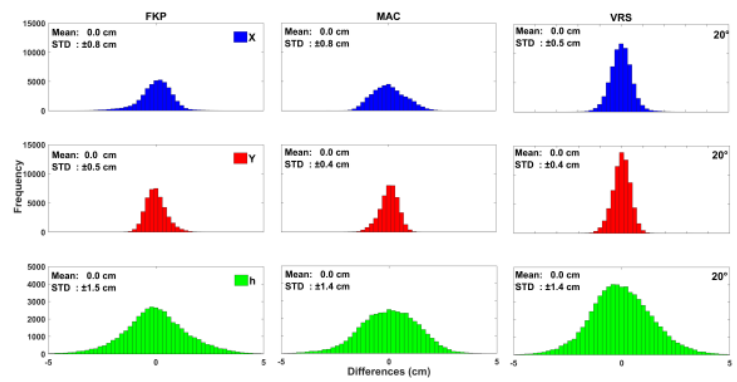

Figure 6. Histograms of differences in measurements of 12-19 hour, using the FKP-MAC-VRS correction techniques (elevation cut-off angle: 20 degree).

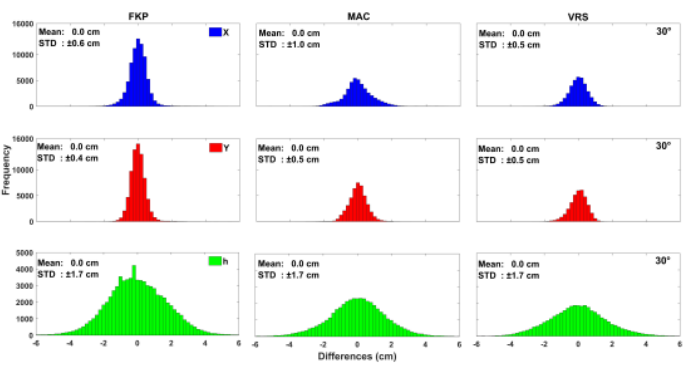

Figure 7. Histograms of differences in measurements of 10-21 hour, using the FKP-MAC-VRS correction techniques (elevation cut-off angle: 30 degree).

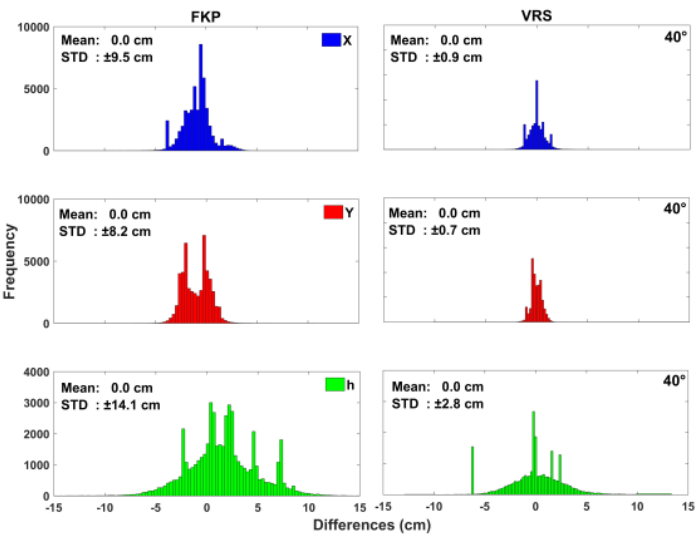

Figure 8. Histograms of differences in measurements of 7-14 hour, using the FKP-MAC-VRS correction techniques (elevation cut-off angle: 40 degree). 
The exact coordinates of the point where the measurements were performed were determined using the Leica Geo Office program based on the CORS-TR network. The coordinates were accepted as exact value and the differences of the mean value of each observation from the exact value were taken. Table 2 presents the differences of the mean values of observations with 11 different combinations. As can be seen from Table 2, the horizontal components are consistent at all levels of correction techniques and at a sub-cm level at all elevation cut-off angle. But in the elevation component, it is seen that as the elevation cut-off angle increases, the differences increase.

Table 2. Differences of the mean values of observations with 11 different combinations from the exact value

\begin{tabular}{|c|c|c|c|c|}
\hline \multirow{2}{*}{\multicolumn{2}{|c|}{}} & \multicolumn{3}{|c|}{ Differences (cm) } \\
\cline { 3 - 5 } & $\mathrm{X}$ & $\mathrm{Y}$ & $\mathrm{h}$ \\
\hline \multirow{3}{*}{$\begin{array}{c}\text { 10 } \\
\circ\end{array}$} & FKP & 0,0 & 0,6 & $-2,5$ \\
& MAC & 0,3 & 0,8 & $-0,8$ \\
& VRS & $-0,6$ & 0,2 & $-2,7$ \\
\hline \multirow{3}{*}{20} & FKP & $-0,3$ & 0,8 & $-2,1$ \\
$\circ$ & MAC & 0,8 & 0,9 & $-2,1$ \\
& VRS & $-0,5$ & 0,2 & $-2,7$ \\
\hline \multirow{3}{*}{30} & FKP & $-0,2$ & 0,6 & $-3,1$ \\
$\circ$ & MAC & 0,9 & 0,8 & $-3,5$ \\
& VRS & $-0,4$ & 0,2 & $-4,1$ \\
\hline \multirow{3}{*}{40} & FKP & 0,6 & 1,2 & $-6,0$ \\
& MAC & - & - & - \\
& VRS & $-0,6$ & 0,0 & $-5,3$ \\
\hline
\end{tabular}

Table 3 contains the results of the statistical analysis of the differences obtained from 11 different combinations. According to the results obtained from the environment where the satellite view was open, all three methods provided similar results concerning the standard deviations of position and height components. When the minimum and maximum values were analyzed, the VRS technique produced better results compared to the MAC method for the $\mathrm{X}$ and $\mathrm{Y}$ components, while MAC performed better for the height component (Kahveci, 2009). The results related to the partially closed environment revealed that the standard deviation results of the $\mathrm{X}, \mathrm{Y}$ and $\mathrm{h}$ components were similar to the values obtained under the $10^{\circ}$ elevation angle for all three methods. Concerning the minimum and maximum values, MAC had better performance than the VRS method for the X, Y and h components. Lastly, when the satellite view was limited, the standard deviation performance of the $\mathrm{X}, \mathrm{Y}$ and $\mathrm{h}$ components were similar for the three methods. However, according to the minimum and maximum values, the highest performance belonged to the VRS technique. As mentioned before, in cases where the satellite view is limited, MAC does not provide any data.

Table 4 contains the percentage distribution of error amounts which the three components $(\mathrm{X}, \mathrm{Y}, \mathrm{h})$ and positioning $(\mathrm{P})$ parameters obtained from 11 different data sets. We can explain that the concept of error used in here. The error values $( \pm \sigma)$ found for each element of the $\mathrm{X}, \mathrm{Y}$ and $\mathrm{h}$ time series is the error found by subtracting each measure from the mean value of the corresponding time series. The error amount of the position parameter refers to the square root value of the sum of the squares of $\mathrm{X}$ and $\mathrm{Y}$ values.

Table 3. Statistical Analysis of Data.

\begin{tabular}{|c|c|c|c|c|c|c|c|c|c|c|}
\hline \multirow{2}{*}{$\begin{array}{l}\text { Cut- } \\
\text { Off } \\
\text { Angle }\end{array}$} & \multirow{2}{*}{$\begin{array}{l}\text { Correction } \\
\text { Technique }\end{array}$} & \multicolumn{3}{|c|}{ Std. $(\mathrm{cm})$} & \multicolumn{3}{|c|}{ Min. (cm) } & \multicolumn{3}{|c|}{$\operatorname{Max} .(\mathrm{cm})$} \\
\hline & & $\mathrm{X}$ & $\mathrm{Y}$ & $\mathrm{h}$ & $\mathrm{X}$ & $\mathrm{Y}$ & $\mathrm{h}$ & $X$ & $\mathrm{Y}$ & $\mathrm{h}$ \\
\hline \multirow{3}{*}{$10^{\circ}$} & FKP & 0,7 & 0,5 & 1,5 & $-2,9$ & $-3,1$ & $-6,6$ & 3,3 & 2,4 & 13,9 \\
\hline & MAC & 0,6 & 0,4 & 1,3 & $-2,2$ & $-1,6$ & $-5,2$ & 2,3 & 2,1 & 5,5 \\
\hline & VRS & 0,5 & 0,4 & 1,3 & $-2,0$ & $-2,3$ & $-6,2$ & 2,2 & 1,9 & 9,3 \\
\hline \multirow{3}{*}{$20^{\circ}$} & FKP & 0,8 & 0,5 & 1,5 & $-3,8$ & $-1,7$ & $-6,7$ & 2,9 & 2,1 & 8,2 \\
\hline & MAC & 0,8 & 0,4 & 1,4 & $-2,9$ & $-2,9$ & $-2,1$ & $-6,0$ & 1,4 & 4,7 \\
\hline & VRS & 0,5 & 0,4 & 1,4 & $-2,4$ & $-1,9$ & $-6,4$ & 8,2 & 3,3 & 6,0 \\
\hline \multirow{3}{*}{$30^{\circ}$} & FKP & 0,6 & 0,4 & 1,7 & $-4,2$ & $-2,9$ & $-10,0$ & 5,2 & 5,5 & 12,5 \\
\hline & MAC & 1,0 & 0,5 & 1,7 & $-4,8$ & $-3,5$ & $-9,8$ & 7,5 & 2,9 & 8,7 \\
\hline & VRS & 0,5 & 0,5 & 1,7 & $-3,2$ & $-2,8$ & $-7,6$ & 2,3 & 1,9 & 9,9 \\
\hline \multirow{3}{*}{$40^{\circ}$} & FKP & 9,5 & 8,2 & 14,1 & $-44,6$ & $-44,3$ & $-176,1$ & $-127,5$ & 72,3 & 15,9 \\
\hline & MAC & - & - & - & - & - & - & - & - & - \\
\hline & VRS & 0,9 & 0,7 & 2,8 & $-48,8$ & $-4,0$ & $-13,9$ & 5,5 & 56,3 & 12,6 \\
\hline
\end{tabular}


In Table 4, the error amounts for each time series (X, $\mathrm{Y}, \mathrm{P}, \mathrm{h})$ were expressed in the percentage and the comparison was intended to be simplified. The expression "100" indicates that all error values remain within the range of the given error. This analysis includes that the inspection up to $7 \mathrm{~cm}$ of errors in accordance with applicable regulations in Turkey.

Using different correction techniques under the $10^{\circ}$ satellite view, the $\mathrm{X}, \mathrm{Y}$ and $\mathrm{P}$ components were below 4 $\mathrm{cm}$, whereas the " $\mathrm{h}$ " component reached $5 \mathrm{~cm}$ for MAC, $6 \mathrm{~cm}$ for VRS, and $7 \mathrm{~cm}$ for FKP. It was observed that $90 \%$ of the $\mathrm{X}, \mathrm{Y}$ and $\mathrm{P}$ component results obtained using the VRS technique were between 0 and $1 \mathrm{~cm}$.
Furthermore, for the height measurement, VRS provided the most accurate results.

The results obtained from the $20^{\circ}$ satellite view showed that the $\mathrm{Y}$ component was below $3 \mathrm{~cm}$ for all three corrective techniques, the $\mathrm{X}$ component was below $3 \mathrm{~cm}$ for MAC and VRS and below $4 \mathrm{~cm}$ for FKP. Similar to the $10^{\circ}$, the height component was below $5 \mathrm{~cm}$ for MAC, and below 6 and $7 \mathrm{~cm}$ for VRS and FKP, respectively. It is suggested that the VRS technique is more efficient in measuring $\mathrm{X}, \mathrm{Y}$ and $\mathrm{P}$, whereas all three techniques have similar performance for height measurements.

Table 4. Error distribution of differences in percentages.

\begin{tabular}{|c|c|c|c|c|c|c|c|c|c|c|c|c|c|}
\hline \multirow{2}{*}{$\begin{array}{l}\text { Diff. } \\
(\mathrm{cm})\end{array}$} & \multirow{2}{*}{ Data } & \multicolumn{3}{|c|}{$10^{\circ}$} & \multicolumn{3}{|c|}{$20^{\circ}$} & \multicolumn{3}{|c|}{$30^{\circ}$} & \multicolumn{3}{|c|}{$40^{\circ}$} \\
\hline & & FKP & MAC & VRS & FKP & MAC & VRS & FKP & MAC & VRS & FKP & MAC & VRS \\
\hline \multirow{4}{*}{$0-1$} & $X$ & 89,2 & 92,9 & 96,9 & 85,7 & 79,8 & 95,3 & 93,9 & 70,8 & 93,6 & 51,1 & - & 78,2 \\
\hline & $\mathrm{Y}$ & 95,5 & 97,1 & 97,8 & 96,7 & 97,5 & 98,2 & 97,5 & 93,4 & 93,7 & 55,0 & - & 92,0 \\
\hline & $\mathrm{P}$ & 82,6 & 87,3 & 92,2 & 79,7 & 73,3 & 90,7 & 88,7 & 60,7 & 84,1 & 23,7 & - & 66,6 \\
\hline & $\mathrm{h}$ & 53,7 & 58,3 & 59,6 & 54,3 & 55,6 & 53,5 & 44,2 & 47,9 & 46,9 & 17,7 & - & 39,0 \\
\hline \multirow{4}{*}{$<2$} & $X$ & 98,8 & 99,9 & 100,0 & 97,3 & 99,5 & 99,9 & 99,3 & 97,2 & 99,9 & 87,7 & - & 98,8 \\
\hline & $\mathrm{Y}$ & 99,9 & 100,0 & 100,0 & 100,0 & 100,0 & 100,0 & 99,7 & 99,7 & 99,9 & 96,3 & - & 100,0 \\
\hline & $\mathrm{P}$ & 98,1 & 99,7 & 99,9 & 96,5 & 99,3 & 99,8 & 98,8 & 95,9 & 99,4 & 68,9 & - & 98,4 \\
\hline & $\mathrm{h}$ & 85,3 & 89,1 & 88,7 & 83,0 & 87,1 & 84,6 & 75,7 & 78,5 & 76,9 & 43,9 & - & 63,0 \\
\hline \multirow{4}{*}{$<3$} & $\mathrm{X}$ & 100,0 & 100,0 & 100,0 & 99,8 & 100,0 & 100,0 & 99,8 & 99,5 & 100,0 & 97,5 & - & 99,8 \\
\hline & $\mathrm{Y}$ & 100,0 & 100,0 & 100,0 & 100,0 & 100,0 & 100,0 & 100,0 & 100,0 & 100,0 & 98,2 & - & 100,0 \\
\hline & $\mathrm{P}$ & 99,9 & 100,0 & 100,0 & 99,6 & 100,0 & 100,0 & 99,7 & 99,4 & 100,0 & 96,5 & - & 99,8 \\
\hline & $\mathrm{h}$ & 95,7 & 97,7 & 97,1 & 94,8 & 96,7 & 95,9 & 91,8 & 92,5 & 91,7 & 63,4 & - & 79,6 \\
\hline \multirow{4}{*}{$<4$} & $X$ & 100,0 & 100,0 & 100,0 & 100,0 & 100,0 & 100,0 & 100,0 & 99,7 & 100,0 & 98,2 & - & 100,0 \\
\hline & $\mathrm{Y}$ & 100,0 & 100,0 & 100,0 & 100,0 & 100,0 & 100,0 & 100,0 & 100,0 & 100,0 & 98,4 & - & 100,0 \\
\hline & $\mathrm{P}$ & 100,0 & 100,0 & 100,0 & 100,0 & 100,0 & 100,0 & 99,9 & 99,6 & 100,0 & 98,0 & - & 100,0 \\
\hline & $\mathrm{h}$ & 98,3 & 99,6 & 99,2 & 98,9 & 99,4 & 99,2 & 97,7 & 97,7 & 97,7 & 76,8 & - & 87,3 \\
\hline \multirow{4}{*}{$<5$} & $X$ & 100,0 & 100,0 & 100,0 & 100,0 & 100,0 & 100,0 & 100,0 & 100,0 & 99,8 & 98,3 & - & 100,0 \\
\hline & $\mathrm{Y}$ & 100,0 & 100,0 & 100,0 & 100,0 & 100,0 & 100,0 & 100,0 & 100,0 & 100,0 & 98,4 & - & 100,0 \\
\hline & $\mathrm{P}$ & 100,0 & 100,0 & 100,0 & 100,0 & 100,0 & 100,0 & 100,0 & 99,8 & 100,0 & 98,3 & - & 100,0 \\
\hline & $\mathrm{h}$ & 99,4 & 100,0 & 99,7 & 99,8 & 100,0 & 99,9 & 99,3 & 99,2 & 99,3 & 84,5 & - & 90,8 \\
\hline \multirow{4}{*}{$<6$} & $X$ & 100,0 & 100,0 & 100,0 & 100,0 & 100,0 & 100,0 & 100,0 & 100,0 & 100,0 & 98,4 & - & 100,0 \\
\hline & $\mathrm{Y}$ & 100,0 & 100,0 & 100,0 & 100,0 & 100,0 & 100,0 & 100,0 & 100,0 & 100,0 & 98,4 & - & 100,0 \\
\hline & $\mathrm{P}$ & 100,0 & 100,0 & 100,0 & 100,0 & 100,0 & 100,0 & 100,0 & 99,9 & 100,0 & 98,4 & - & 100,0 \\
\hline & $\mathrm{h}$ & 99,8 & 100,0 & 99,9 & 100,0 & 100,0 & 100,0 & 99,8 & 99,6 & 99,8 & 87,9 & - & 92,5 \\
\hline \multirow{4}{*}{$<7$} & $X$ & 100,0 & 100,0 & 100,0 & 100,0 & 100,0 & 100,0 & 100,0 & 100,0 & 100,0 & 98,4 & - & 100,0 \\
\hline & $\mathrm{Y}$ & 100,0 & 100,0 & 100,0 & 100,0 & 100,0 & 100,0 & 100,0 & 100,0 & 100,0 & 98,4 & - & 100,0 \\
\hline & $\mathrm{P}$ & 100,0 & 100,0 & 100,0 & 100,0 & 100,0 & 100,0 & 100,0 & 100,0 & 100,0 & 98,4 & - & 100,0 \\
\hline & $\mathrm{h}$ & 99,9 & 100,0 & 100,0 & 100,0 & 100,0 & 100,0 & 99,9 & 99,8 & 100,0 & 89,3 & - & 93,2 \\
\hline
\end{tabular}


Under the $30^{\circ}$ satellite view, the results obtained using the VRS technique showed that the $\mathrm{X}, \mathrm{Y}, \mathrm{P}$ and $\mathrm{h}$ components were all below $4 \mathrm{~cm}$ whereas the FKP and MAC technique revealed that the position components were close to $6 \mathrm{~cm}$ and the height component reached 7 $\mathrm{cm}$. The FKP technique despite its performance where satellite view was clear $\left(10^{\circ}\right.$ satellite view $)$ or partially blocked ( $20^{\circ}$ satellite view), appeared to be more effective than the other two techniques. As mentioned earlier in this paper, under the $40^{\circ}$ satellite view, no data was obtained from the MAC technique. In the same view, it was observed that VRS was superior to the FKP technique.
FKP
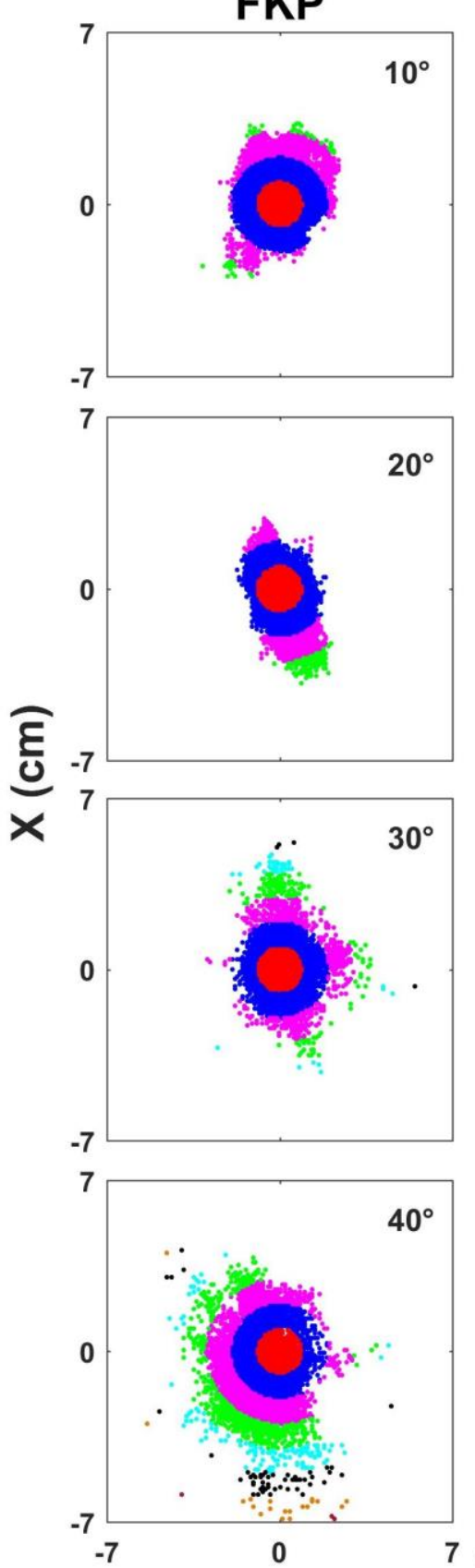
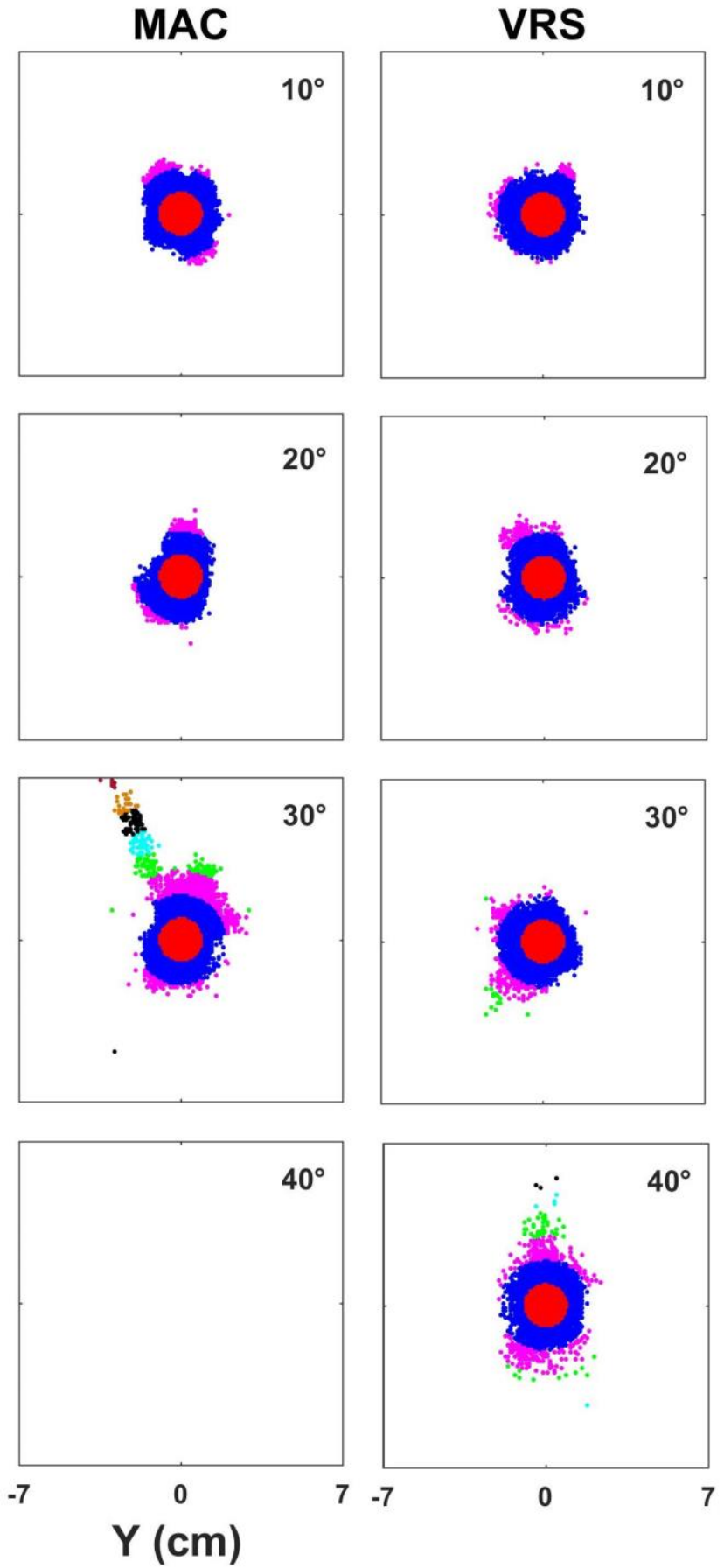

Figure 9. Error Distribution of the Horizontal Position Coordinates.

Figure 9 shows the distribution of the positioning analysis errors obtained from four different satellite angles using three different correction techniques. The colors in this figure represent the error distribution according to the order in Table 4 . As a result of the evaluations based on all satellite views and correction techniques, approximately $85 \%$ of the measurements were within 0 to $1 \mathrm{~cm}$ and approximately $12 \%$ were within 1 to $2 \mathrm{~cm}$. 
Table 5 shows that the percentage distribution of the errors reached $7 \mathrm{~cm}$. When the data obtained by the FKP, MAC and VRS correction techniques under the $10^{\circ}$ satellite view were analyzed, it was determined that the VRS technique gave better results than the FKP for $\mathrm{X}$ and $\mathrm{Y}$ and MAC for $\mathrm{X}, \mathrm{Y}$, and $\mathrm{h}$ analyses. Among the three correction techniques, FKP provided the worst results. For the $20^{\circ}$ satellite view, the errors in the $\mathrm{X}$ and $\mathrm{Y}$ analyses were smaller than $4 \mathrm{~cm}$ and those in the $\mathrm{X}, \mathrm{Y}$ and $\mathrm{h}$ analyses were less than $5 \mathrm{~cm}$ when the MAC technique was applied. However, when the percentage of errors were analyzed, it was seen that the technique with the best result was VRS, whereas MAC performed the worst. For the $30^{\circ}$ satellite view, the FKP technique was partially better or similar compared to VRS. Similar to $20^{\circ}$, MAC gave the worst results in all three methods. In the analyses of $40^{\circ}$ satellite view, VRS achieved better results than FKP for all components. The errors of VRS concerning the $\mathrm{X}, \mathrm{Y}$, and $\mathrm{h}$ components were less than $4 \mathrm{~cm}$, and this method performed well even under very limited satellite view. In the analysis of the combination of the three position components, the FKP method showed poor performance.

Table 5: Cumulative Errors of 2D and 3D Analysis of Data Obtained from Test measurements.

\begin{tabular}{|c|c|c|c|c|c|c|c|c|c|c|c|c|c|}
\hline \multirow{2}{*}{$\begin{array}{l}\text { Diff. } \\
(\mathrm{cm})\end{array}$} & \multirow{2}{*}{ Data } & \multicolumn{3}{|c|}{$10^{\circ}$} & \multicolumn{3}{|c|}{$20^{\circ}$} & \multicolumn{3}{|c|}{$30^{\circ}$} & \multicolumn{3}{|c|}{$40^{\circ}$} \\
\hline & & FKP & MAC & VRS & FKP & MAC & VRS & FKP & MAC & VRS & FKP & MAC & VRS \\
\hline \multirow{2}{*}{$0-1$} & $\mathrm{X}, \mathrm{Y}$ & 85,9 & 90,6 & 94,9 & 84,3 & 78,3 & 93,8 & 91,9 & 67,3 & 88,5 & 32,1 & - & 71,5 \\
\hline & $\mathrm{X}, \mathrm{Y}, \mathrm{h}$ & 48,3 & 53,6 & 56,7 & 46,1 & 44,3 & 50,1 & 41,5 & 33,4 & 42,4 & 6,3 & - & 33,8 \\
\hline \multirow{2}{*}{$<2$} & $X, Y$ & 98,7 & 99,9 & 100,0 & 93,8 & 99,5 & 99,9 & 99,0 & 97,1 & 99,8 & 86,0 & - & 98,8 \\
\hline & $\mathrm{X}, \mathrm{Y}, \mathrm{h}$ & 84,8 & 89,0 & 88,6 & 50,1 & 86,8 & 84,5 & 75,2 & 76,7 & 76,7 & 40,9 & - & 62,7 \\
\hline \multirow{2}{*}{$<3$} & $X, Y$ & 100,0 & 100,0 & 100,0 & 99,8 & 100,0 & 100,0 & 99,8 & 99,5 & 100,0 & 97,3 & - & 99,8 \\
\hline & $\mathrm{X}, \mathrm{Y}, \mathrm{h}$ & 95,7 & 97,7 & 97,1 & 94,6 & 96,7 & 95,9 & 91,6 & 92,4 & 91,7 & 63,0 & - & 79,5 \\
\hline \multirow{2}{*}{$<4$} & $\mathrm{X}, \mathrm{Y}$ & 100,0 & 100 & 100,0 & 100,0 & 100,0 & 100,0 & 99,9 & 99,7 & 100,0 & 98,1 & - & 100,0 \\
\hline & $\mathrm{X}, \mathrm{Y}, \mathrm{h}$ & 98,3 & 99,6 & 99,2 & 98,9 & 99,4 & 99,2 & 97,6 & 97,6 & 97,7 & 76,7 & - & 87,3 \\
\hline \multirow{2}{*}{$<5$} & $\mathrm{X}, \mathrm{Y}$ & 100,0 & 100,0 & 100,0 & 100,0 & 100,0 & 100 & 100,0 & 99,8 & 100 & 98,3 & - & 100,0 \\
\hline & $\mathrm{X}, \mathrm{Y}, \mathrm{h}$ & 99,4 & 100,0 & 99,7 & 99,8 & 100,0 & 99,9 & 99,3 & 99,2 & 99,3 & 84,5 & - & 90,8 \\
\hline \multirow{2}{*}{$<6$} & $\mathrm{X}, \mathrm{Y}$ & 100 & 100,0 & 100,0 & 100,0 & 100,0 & 100,0 & 100,0 & 100,0 & 100,0 & 98,4 & - & 100,0 \\
\hline & $\mathrm{X}, \mathrm{Y}, \mathrm{h}$ & 99,8 & 100,0 & 99,9 & 100,0 & 100,0 & 100,0 & 99,8 & 99,6 & 99,8 & 87,8 & - & 92,5 \\
\hline \multirow{2}{*}{$<7$} & $\mathrm{X}, \mathrm{Y}$ & 100,0 & 100,0 & 100,0 & 100,0 & 100,0 & 100,0 & 100,0 & 100,0 & 100,0 & 98,4 & - & 100,0 \\
\hline & $\mathrm{X}, \mathrm{Y}, \mathrm{h}$ & 99,9 & 100,0 & 100,0 & 100,0 & 100,0 & 100,0 & 99,9 & 99,8 & 100,0 & 89,3 & - & 93,2 \\
\hline
\end{tabular}

\section{CONCLUSION}

In order to test the repeatability of the network of RTK measurements, at previously known fixed coordinates and different elevation cut-off angle, longterm data were collected using three different correction techniques (FKP, MAC and VRS) with a one-second epoch interval. In this study, the repeatability of the horizontal and vertical coordinate from each combination was analyzed. When the standard deviation and minimum-maximum values were examined, three correction techniques had similar performance for $10^{\circ}$ and $20^{\circ}$ elevation cut-off angle, and after increasing the elevation cut-off angle, there was an increase in the standard deviation of the $\mathrm{h}$ component. In the analysis of $\mathrm{X}, \mathrm{Y}, \mathrm{P}$ and $\mathrm{h}$ components, it was seen that the performance of the three correction techniques was generally similar, but the VRS technique yielded slightly better results. However, when $2 \mathrm{D}$ and $3 \mathrm{D}$ coordinate components were analyzed together, it was clear that the VRS technique gave better results compared to the other two techniques. Furthermore, even in the case of limited

satellite vision, errors in all three techniques remained below $7 \mathrm{~cm}$. This $7 \mathrm{~cm}$ error value in the study, according to the relevant current regulations in Turkey (Large Scale Map and Map Information Production Regulation - 2018) is an appropriate result. In the current conditions, considering both time and cost, static CORS-TR measurements make a great contribution to the users in terms of the accuracy provided.

\section{REFERENCES}

Seeber, G. (2003). Setallite Geodesy, Foundations, Methods and Applications, second edition, de Gruyer.

Gumus, K., Celik, C., Erkaya H. (2012). Investigation Of Accurate Method In 3-D Position Using Cors-Net In Istanbul. 
Sunantyo, T. Aris. (2009). GNSS CORS Infrastructure and Standard in Indonesia. 7th FIG Regional Conference, Spatial Data Serving People: Land Governance and the Environment - Building the Capacity, Hanoi, Vietnam, 19-22 October.

Öcalan, T., Tunalığlu, N. (2010). Data communication for real-time positioning and navigation in global navigation satellite systems (GNSS)/continuously operating reference stations (CORS) Networks. Sci. Res. Essays,Vol. 5(18), pp. 2630-2639.

Wanninger L., (2003). Virtual reference stations (VRS). GPS Solutions 7:143-144.

Wübena G., Bagge A. (1998). GNSS multi-station adjustment for permanent deformation analysis networks, Symp. on Geodesy for Geotechnical \& Structural Engineering of the IAG Special Commission 4, Eisenstadt, Austria, 20-22 April, 139-144.

Brown N., Keenan R., Richter B., Troyer L. (2005). Advances in ambiguity resolution for RTK applications using the new RTCM V3.0 Master-Auxiliary messages. In: Proc ION GNSS 2005, Long Beach, California, September 13-16.

Eren K., Uzel T., Gülal E., Yıldırım O., Cingöz A. (2009) Results from a Comprehensive Global Navigation Satellite System Test in the CORS-TR Network: Case Study.

Bütün O. F., Baybura T. (2010). Tusaga Aktif (Cors-TR) Istayonlarınıdan Elde edilen Nokta Koordinat Dogrulugunun Incelenmesi, 5. Ulusal Muhendislik Olcmeleri Semposyumu, 20-22 Ekim 2010, Zonguldak, Turkiye.

Bulbul S., Inal C., Yildirim O. and Basciftci F. (2017). Velocity Estimation of Turkish National Permanent GNSS Network- Active Points Located at Central Anatolia Region. Bilge International Journal of Science and Technology Research, 1(Special Issue), 18-25, 2017

Purtı A. (2016). The Seasonal Effects Of Deciduous Tree Foliage In Cors-Gnss Measurements (Vrs/Fkp).

Gümüş K., Selbesoğu M., Celik C. (2016). Accuracy investigation of height obtained from Classical and Network RTK with ANOVA Test.

Öğütücü S., Kalaycı I. (2016). Investigation of networkbased RTK techniques: a case study in urban area.

Musa T., A., Lim S., Rizos C. (2005). Low latitude troposphere: A preliminary study using GPS CORS data in South East Asia. U.S. Institute of Navigation National Tech. Meeting, San Diego, California, January 24-26, pp. 685-693.

Brownjohn J. M., Rizos C, Tan G. H., Pan T. C. (2004). Real-time long-term monitoring and static and dynamic displacements of an office tower, combining RTK GPS and accelerometer data. 1st FIG Int. Symp. On Engineering Surveys for Construction Works \& Structural Engineering.
Kempe C., Alfredsson A., Engberg L. E., Lilje M. (2006). Correction model to rectify distorted co-ordinate system. XXIII FIG Congress.

Yıldırım O., Yaprak S., Inal C. (2013). Determination of 2011 Van/Turkey earthquake $(M=7.2)$ effects from measurements of CORS-TR network.

Mekik C., Yildirim O., Bakici S. (2011). The Turkish real time kinematic GPS network (TUSAGA-Active) infrastructure. Sci Res Essays. 6(19):3986-3999.

Aykut N. O., Gülal E., Akpınar B. (2015). Performance of Single Base RTK GNSS Method versus Network RTK, Earth Sci. Res. J. Vol. 19, No. 2 (December, 2015): 135 $-139$.

Uzel T., Eren K., Gulal E., Dindar A., Tiryakioglu I., Yilmaz H. (2011). Tectonic plate displacement monitoring with TUSAGA - Active (CORS-TR) data. Paper presented at: 13th Turkey Map Scientific and Technical Conference; Ankara, Turkey (In Turkish).

Kahveci M. (2009). Kinematik GNSS ve RTK CORS Ağları.

Park, B. and Kee, C. (2010). The Compact Network RTK Method: An Effective Solution to Reduce GNSS Temporal and Spatial Decorrelation Error. J. Navig., 63, 343-362.

Landau H. Vollath U. Chen X. (2003). Virtual Reference Stations, Joumal of Global Positioning System, (2): 137143.

Raquet, J. (1998). Development of a Method for Kinematic GPS Carrier-Phase Ambiguity Resolution Using Multiple Reference Receivers. PhD Thesis, University of Calgary.

Rizos, C. (2002). Network RTK Research and Implementation -A GeodeticPerspective, Journal of Global PositioningSystems, Vol.1, No.2:144- 150.

Kim, J., Song, J., No, H., Han, D., Kim, D., Park, B., Kee, C. (2017). Accuracy Improvement of DGPS for LowCost Single-Frequency Receiver Using Modified Flächen Korrektur Parameter Correction, ISPRS International Journal of Geo-Information 6 (7) : 222.

Bascifci, F., Inal, C., Yildirim, O., Bülbül, S. (2018). Comparison Of Regional And Global Tec Values: Turkey Model, International Journal of Engineering And Geosciences, 3(2), 61-72.

Tusat, E., Ozyuksel, F. (2018). Comparison of GPS Satellite Coordinates Computed From Broadcast and IGS Final Ephemeridides, International Journal of Engineering and Geosciences (IJEG),3 (1), 012-019. 